Bangladesh J. Plant Taxon. 28(1): 75-81, 2021 (June)

(C) 2021 Bangladesh Association of Plant Taxonomists

https://doi.org/10.3329/bjpt.v28i1.54209

\title{
MOLECULAR CHARACTERIZATION OF CANNA INDICA L. BASED ON RANDOM AMPLIFIED POLYMORPHIC DNA MARKERS
}

\author{
Sabiha Sultana Akhi, Bivas Kumar Sarkar, Nahid Sultana, \\ Zakya Sultana Jui ${ }^{1}$, R.H. SarkeR ${ }^{2}$ and M. Oliur Rahman ${ }^{2} *$ \\ Department of Botany, Jagannath University, Dhaka 1100, Bangladesh
}

Keywords: Canna indica L.; Molecular identification; Variant; RAPD; Genetic diversity; UPGMA.

\begin{abstract}
Random amplified polymorphic DNA (RAPD) markers were employed for characterization, assessment of genetic variation and inferring relationships among six variants of Canna indica L. A total of 198 RAPD bands ranging from $200 \mathrm{bp}$ to $3 \mathrm{kbp}$ were generated by all the six variants. Among them, most of the bands were found to be polymorphic, four band were unique of which two bands (OPA02 2000 and OPA04 $\left.{ }_{3000}\right)$ were observed in the variant 2 (small red) and the other two (OPA01 3000 and OPA05 3000$)$ were noticed in the variant 4 (orange), and the remaining bands were found to be monomorphic. The pair-wise genetic distance was determined among the six variants that ranged from 0.1446 to 0.6554 . A dendogram was constructed based on the RAPD profiling to infer the relationship among the six variants of $C$. indica that resulted in two major clusters: the first one contained two variants, viz. variant 1 (local red) and variant 2 (small red), while the second cluster composed of the remaining four variants. The results as revealed from the RAPD analysis were found congruent with those of morphological and anatomical investigation of the species.
\end{abstract}

\section{Introduction}

The family Cannaceae, comprising the single genus Canna L. is widely distributed throughout the tropical regions. Cannas are worthy garden perennials because of their ornamental value, and the flowering perennial carries an exotic beauty to garden sites with its showy flowers and sometimes with very colourful leaves. In global context, Cannas are one of the popular garden plants, and a large horticultural industry depends on this plant. The commonly cultivated garden Cannas are mostly of hybrid origin, with Canna indica as the principal parent (Cronquist, 1981). The genus Canna is composed of only 8-10 wild species, and over 1,000 hybrids which are used as garden ornamentals in Europe, North America and many tropical countries (Patra et al., 2008). Canna is considered to be native in Mexico, Central America, the Caribbean and tropical South America, West Indies and Central America (Heywood, 1993). In Bangladesh, Canna is represented by a single species, Canna indica, and is found in almost all over the country as well as planted in many gardens.

The genus Canna testifies economical, horticultural and medicinal values. The rhizome of Cannas is rich in starch with multifarious uses in agriculture. Rootstock of Canna indica is diaphoretic, diuretic and demulcent, and decoction of root is used in fevers, dropsy and dyspepsia. Seed extract is administered for relieving earache (Ghani, 2003). Young shoots are eaten as green vegetables. The leaves are suitable for wrapping and as plates; both the leaves and the rhizomes

${ }^{1}$ Department of Botany, Bangabandhu Sheikh Mujibur Rahman Science \& Technology University, Gopalganj 8100, Bangladesh.

${ }^{2}$ Department of Botany, University of Dhaka, Dhaka 1000, Bangladesh.

*Corresponding author. Email: oliur.bot@ du.ac.bd 
are used as fodder. Fumigated stems and leaves are used as insecticide (Ong and Siemonsma, 1996). A pure dye is obtained from seeds. Fibre is obtained from the stem which is used as a jute substitute.

RAPDs (Random Amplified Polymorphic DNAs) are widely used molecular markers where DNA fragments are amplified by the Polymerase Chain Reaction (PCR) using short oligonucleotide primers (Williams et al., 1990). RAPD markers are found to be useful in molecular characterization (Islam et al., 2020), DNA fingerprinting (Hossain et al, 2002), assessment of genetic diversity (Karande et al., 2017), cultivar identification (Venkatachalam et al., 2008), taxonomic problems (Vilatersana et al., 2005), systematic relationships (Rahman, 2010), phylogeny reconstruction (Poczail et al., 2008), population genetic structure (Sales et al., 2001), species hybridization (Caraway et al., 2001) and linkage mapping (Atienza et al., 2002).

In spite of economical, horticultural and medicinal value, a very few systematic studies were carried out to detect variation in Canna indica. Very recently, Sultana et al. (2019) detected six variants of Canna indica based on morphological and anatomical investigation. However, molecular studies to assess genetic variation in Canna indica are lacking in Bangladesh. Because of universality and reproducibility the RAPD markers were employed to detect genetic diversity of Canna indica. The present study aimed at assessing genetic variation and relationships among the six variants of Canna indica occurring in Bangladesh for the first time.

\section{Materials and Methods}

\section{Plant material:}

Plant specimens of Canna indica were collected from different parts of Bangladesh and were maintained under the controlled climatic condition, and planted in the Botanical Garden of Jagannath University. These were supplemented by the herbarium specimens examined at the Bangladesh National Herbarium (DACB) and Dhaka University Salarkhan Herbarium (DUSH).

\section{Isolation of Genomic DNA:}

DNA was isolated from the leaf tissue ranging from 1.0 to $1.5 \mathrm{~g}$ using CTAB method (Doyle and Doyle 1987). The isolated DNA was dissolved in TE buffer and stored at $-20^{\circ} \mathrm{C}$ until further use.

\section{RAPD amplification:}

A total of 10 decamer oligonucleotide primers were examined, and based on reproducibility the following five primers were finally chosen for RAPD analysis: OPA01 (5'-CAGGCCCTTC3'), OPA02 (5'-TGCCGAGCTG-3'), OPA04 (5'-AATCGGGCTG-3'), OPA05 (5'-AGGGG TCTTG-3') and OPA10 (5'-GTGATCGCAG-3'). Each PCR included $2.0 \mu \mathrm{l}$ of $25 \mathrm{ng}$ genomic DNA, $1.0 \mu \mathrm{l}$ primer, $2.5 \mu \mathrm{l}$ 10X Taq buffer, $0.5 \mu \mathrm{l}$ of dNTP mixture, $0.2 \mu 1$ Taq polymerase enzyme, and $18.8 \mu \mathrm{l}$ sterile, deionised distilled water up to final volume of $25 \mu \mathrm{l}$. PCR reaction was performed in an oil-free thermal cycler (Biometra, UNO II) as per following temperature profile: initial denaturation at $94^{\circ} \mathrm{C}$ for $5 \mathrm{~min}$, denaturation at $94^{\circ} \mathrm{C}$ for $45 \mathrm{~s}$, annealing at $32^{\circ} \mathrm{C}$ (for $60 \% \mathrm{GC}$ rich content primer) and $34^{\circ} \mathrm{C}$ (for $70 \% \mathrm{GC}$ rich content primer) for $30 \mathrm{~s}$, extension at $72^{\circ} \mathrm{C}$ for 3 min followed by 55 cycles. A final 7 min extension at $72^{\circ} \mathrm{C}$ ensured full extension of all amplified fragments.

\section{Gel electrophoresis:}

Amplified PCR products were separated on $1 \%$ agarose gel and stained with ethidium bromide solution. The size of the amplicons was determined using standard $1 \mathrm{~Kb}$ ladder. DNA bands were visualized under UV-transilluminator and photographed. 
Data analysis:

RAPD bands were recorded in a binary data matrix scored as presence (1) or absence (0) for each sample. Similarity Matrix coefficient was used for measuring genetic relationship among the variants analyzed. UPGMA (Unweighted pair group method with arithmetic average) tree was generated by clustering the distance matrix. Data were analyzed using POPGENE32 (Nei, 1972).

\section{Results and Discussion}

RAPD fingerprints:

The present study revealed a total of 198 RAPD fingerprints generated by five oligonucleotide primers ranging from $200 \mathrm{bp}$ to $3 \mathrm{kbp}$ in six variants of Canna indica. The studied five primers generated reproducible bands in all the variants investigated. The number of bands generated by the primers varied within the investigated variants and showed polymorphisms among them.

The primer OPA01 (5'-CAGGCCCTTC-3') generated a total of 50 RAPD bands in the six variants of Canna indica. All the variants presented 4 monomorphic bands each at the same locus $\left(\mathrm{OPA} 01_{2500}, \mathrm{OPA} 01_{1550}, \mathrm{OPA} 01_{900}\right.$ and OPA01 $\left.{ }_{750}\right)$. The highest number of bands (11) was generated by the variant 6 (yellow with red spots) of which 4 bands $(36.36 \%)$ were found to be monomorphic and 7 bands (63.64\%) were polymorphic. The variant 1 (local red) produced the lowest number of bands (6) showing $85.71 \%$ similarities with the variant 2 (small red), and among the 6 bands produced, 4 were monomorphic, while the other 2 were polymorphic. The variant 2 produced 7 bands of which 4 were monomorphic and 3 were polymorphic. The variant 3 (pink) and variant 4 (orange) produced 9 bands each, among them 4 bands were monomorphic and 5 were polymorphic. The variant 5 (yellow) produced 8 RAPD bands at the same locus position of the variant 6 and showed $72.72 \%$ similarities with it. Out of 9 bands generated by the variant 4 one unique band was detected by the primer OPA01 $1_{3000}$ in this variant (Fig. 1a).

The primer OPA02 (5'-TGCCGAGCT G-3') generated the highest number of bands (62) in all the six variants. Among all the variants, the highest number of bands (12) was observed in the variant 6 , of which 7 bands (63.64\%) were monomorphic and 4 (36.36\%) were polymorphic. The lowest number of bands (9) was found in the variant 1 , and among them 7 bands $(77.78 \%$ ) were monomorphic and $2(22.22 \%)$ were polymorphic. The variants 2,3 and 4 generated 10 bands each, among them the variants 3 and 4 showed the same banding pattern (100\% similarities), whereas, the variant 2 displayed $80 \%$ similarities with the variant 4 . In the variant 5 , a total of 11 bands were found of which 7 bands were monomorphic and 4 polymorphic. The variant 5 showed $91.67 \%$ affinity with the variant 6 . One unique band was found in the variant 2 at the OPA02 2000 position (Fig. 1b).

The OPA04 (5'-AATCGGGCTG-3') primer displayed a total of 38 bands among the six variants. The highest number of bands (11) was observed in the variant 2 of which 10 bands $(90.91 \%)$ were polymorphic and 1 was monomorphic. The lowest number of bands (3) was found in the variant 6 and among them 2 bands (66.67\%) were polymorphic and 1 was monomorphic. The variant 1 presented 9 bands of which 8 bands (88.89\%) were polymorphic and 1 was monomorphic. The variant 3 displayed 7 bands and among them 6 bands $(85.71 \%)$ were polymorphic and 1 was found to be common. The variant 4 and the variant 5 both exhibited 4 bands, of which 1 was monomorphic. No unique polymorphic band was generated by the primer OPA04 (Fig. 1c).

The primer OPA05 (5'-AGGGGTCTTG-3') produced a total of 16 bands in six variants. The highest number of bands (7) was found in the variant 4 , among them $1\left(\mathrm{OPA} 05_{3000}\right)$ was unique band and 6 were polymorphic $(85.71 \%)$. No bands were found in the variant 6 . The variants 3 and 
5 produced only 1 polymorphic band at the same position $\left(\mathrm{OPA} 05_{2500}\right)$. The variant 1 showed 5 bands, and all of them were found to be polymorphic and showed $71.43 \%$ similarities with the variant 4. Two polymorphic bands were observed in the variant 2 .

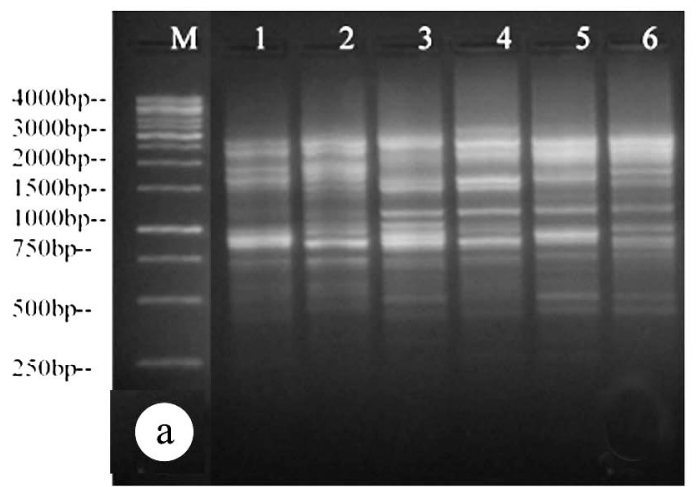

OPA01

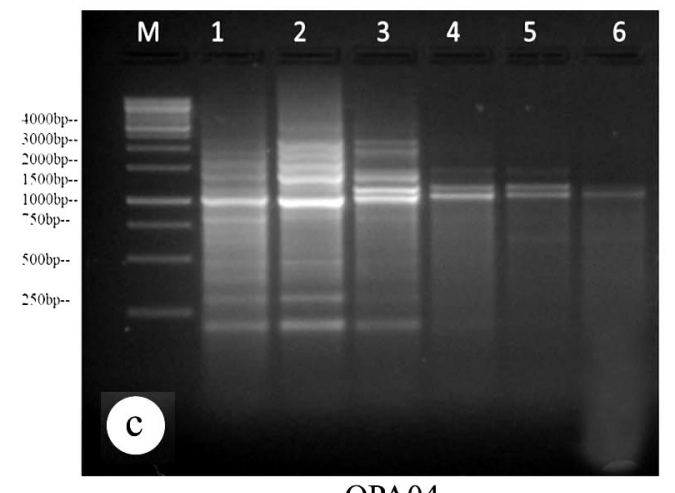

OPA04

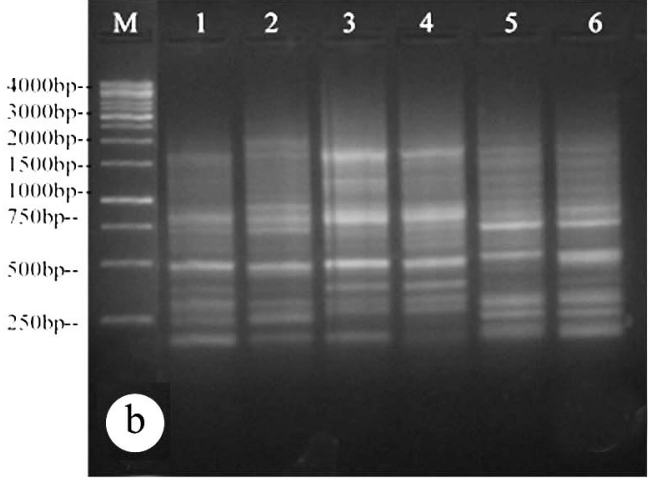

OPA02

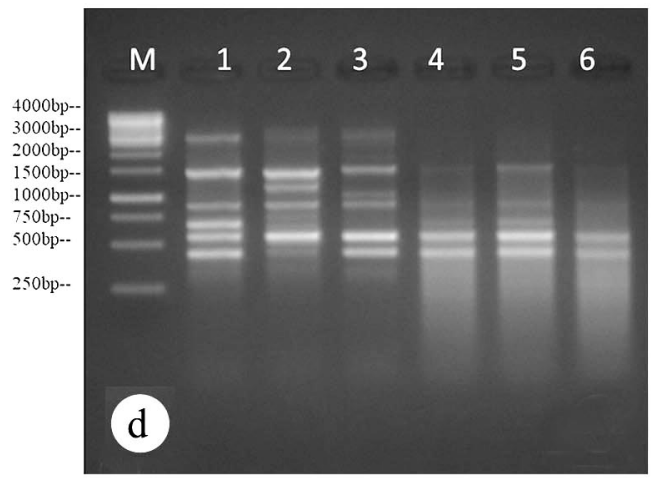

OPA10

Fig. 1. RAPD fingerprints in six variants of Canna indica L.: a. OPA01; b. OPA02: c. OPA04; d. OPA10. M: Molecular marker $(1 \mathrm{~Kb})$; 1. Local red; 2. Small red; 3. Pink; 4. Orange; 5. Yellow; 6. Yellow with red spots.

The primer OPA10 (5'-GTGATCGCAG-3') generated 32 bands in all the six variants. The highest number of bands (6) was found in the variants 1,2 and 3, among which 4 bands were found to be common (66.67\%) and 2 were polymorphic. The similar banding pattern was identified in the variant 2 and variant 3 . The variants 4 and 5 produced 5 bands each, and among them 4 were common and 1 was polymorphic $\left(\mathrm{OPA} 10_{600}\right)$. The variant 6 presented 4 bands and all of them were found to be monomorphic. No unique band was observed in any of the variants (Fig. 1d).

\section{RAPD polymorphism, genetic diversity and molecular relationships}

The present study demonstrated a total of 198 bands generated by 5 primers in all the six variants of Canna indica with an average of 39.6 RAPD loci per primer. The highest polymorphism $(55.56 \%)$ was detected in the variant 2 , while the lowest $(44.83 \%)$ was found in the 
variant 5 . The other variants showed relatively high level of polymorphism (Table 1). The average polymorphism was found to be $51.19 \%$.

Table 1. RAPD fingerprints and polymorphism in six variants of Canna indica.

\begin{tabular}{lclll}
\hline Name of the variants & $\begin{array}{l}\text { Total no. } \\
\text { of bands }\end{array}$ & $\begin{array}{l}\text { No. of } \\
\text { polymorphic } \\
\text { bands }\end{array}$ & $\begin{array}{l}\% \text { of } \\
\text { polymorphism }\end{array}$ & $\begin{array}{l}\text { Average \% of } \\
\text { polymorphism }\end{array}$ \\
\hline 1. Canna indica (local red) & 35 & 19 & 54.29 & \\
2. C. indica (small red) & 36 & 20 & 55.56 & \\
3. C. indica. (pink) & 33 & 17 & 51.53 & 51.19 \\
4. C. indica (orange) & 35 & 19 & 54.29 & \\
5. C. indica (yellow) & 29 & 13 & 44.83 & \\
6. C. indica L (yellow with red spots) & 30 & 14 & 46.67 & \\
\hline
\end{tabular}

The highly reproducible bands ranging from 200 to $3000 \mathrm{bp}$ were scored for assessment of genetic variation among the six variants of Canna indica. Among the five oligonucleotide primers employed in the present study, 50 bands were generated by the primer OPA01, 62 by OPA02, 38 by OPA04, 16 by OPA05 and 32 bands by OPA 10 primer. The highest genetic distance $(0.6554)$ was found between the variants 1 and 6, and between the variants 2 and 4 followed by the genetic distance as observed between the variants 2 and $6(0.6190)$ The same genetic distance (0.4249) was found between the variants 1 and 4 , and 4 and 5 . Among all the variants, the lowest genetic distance (0.1446) was observed between the variants 5 and 6 indicating a close affinity between these two variants (Table 2).

Table 2. Genetic distance among six variants of Canna indica.

\begin{tabular}{lllllll}
\hline Name of the variants & $\begin{array}{l}\text { Var.1- } \\
\text { local red }\end{array}$ & $\begin{array}{l}\text { Var. 2- } \\
\text { small red }\end{array}$ & $\begin{array}{l}\text { Var. 3- } \\
\text { pink }\end{array}$ & $\begin{array}{l}\text { Var. 4- } \\
\text { orange }\end{array}$ & $\begin{array}{l}\text { Var. 5- } \\
\text { Yellow }\end{array}$ & $\begin{array}{l}\text { Var.6 -yellow } \\
\text { with red spot }\end{array}$ \\
\hline Var. 1 - local red & 0 & & & & & \\
Var. 2 - small red & 0.2377 & 0 & & & & \\
Var. 3 - pink & 0.4855 & 0.3403 & 0 & & & \\
Var. 4 - orange & 0.4249 & 0.6554 & 0.4855 & 0 & & \\
Var. 5 - yellow & 0.5500 & 0.5839 & 0.3677 & 0.4249 & 0 & \\
Var. 6 - yellow with red spot & 0.6554 & 0.6190 & 0.3403 & 0.3959 & 0.1446 & 0 \\
\hline
\end{tabular}

UPGMA tree constructed from RAPD fingerprints showed the inter-relationships among the six variants of Canna indica (Fig. 2). The UPGMA analysis in $C$. indica resulted in two major clusters: cluster 1 contained two variants, viz. variant 1 (local red) and variant 2 (small red), while the cluster 2 composed of the remaining four variants, viz. variant 3 (pink), variant 5 (yellow), variant 6 (yellow with red spot) and variant 4 (orange).

In the present investigation, RAPD markers were employed to characterize the six variants of Canna indica alongside with assessments of genetic variation and to infer molecular relationships among the variants. Out of 10 RAPD primers investigated, 5 showed significant amplifications in PCR analysis and altogether produced 198 bands, and the size of the bands ranged from 200 bp to $3.0 \mathrm{kbp}$. Considerable genetic variability existed in the variants of Canna indica. The present 
study revealed that the variants 5 and 6 joined together indicating a close relationships between them, and genetic distance between these two variants was found to be 0.1446 (Fig. 2, Table 2). The study also exposed a close affinity between the variants 1 and 2 where the genetic distance was reported to be 0.2377 (Table 2). The variant 4 was found to be distantly related with other variants. Out of 198 bands generated by five primers in six variants of Canna indica, 102 bands were found to be polymorphic and 96 as monomorphic.

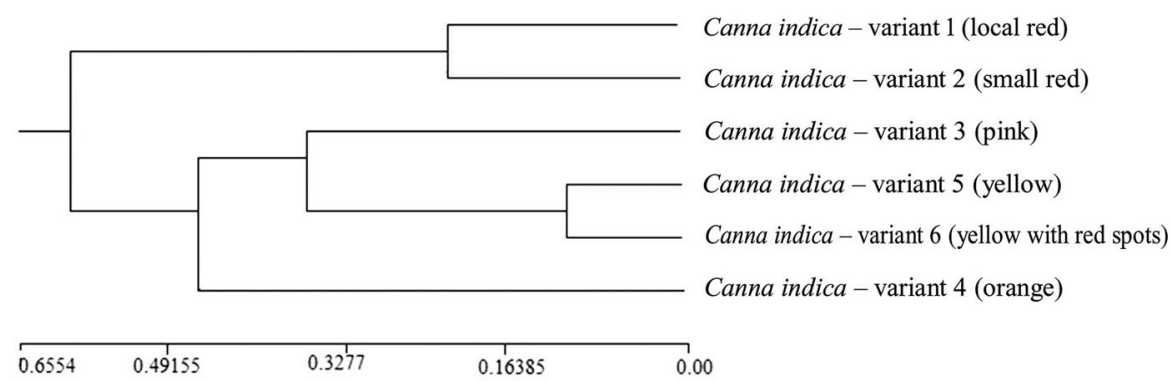

Fig. 2. UPGMA dendogram showing genetic relationships among the six variants of Canna indica as revealed by RAPD markers.

The study exhibited four unique bands, viz. OPA02 2000 and OPA04 $4_{3000}$ as found in the variant 2 and $\mathrm{OPA} 01_{3000}$ and $\mathrm{OPA}_{0} 5_{3000}$ as noticed in the variant 4. The present investigation demonstrated that the average polymorphism within all the variants was found to be $51.195 \%$. Results obtained from the present study were found to be consistent with those of morphological and anatomical investigation among these six variants of Canna indica (Sultana et al., 2019). In order to have better understanding on genetic variation and molecular relationships large number of taxa should be employed with additional molecular markers, such as AFLP, ISSR and microsatellites which will through more light on the phylogeny of Canna indica.

\section{References}

Atienza, S.G., Satovic, Z., Petersen, K.K. Dolstra, O. and Martín, A. 2002. Preliminary genetic linkage map of Miscanthus sinensis with RAPD markers. Theor. Appl. Genet. 105: 946-952.

Caraway V., Carr, G.D. and Morden, C.W. 2001. Assessment of hybridization and introgression in lavacolonizing Hawaiian Dubautia (Asteraceae: Madiinae) using RAPD markers. Am. J. Bot. 88: 16881694.

Cronquist, A. 1981. An Integrated System of Classification of Flowering Plants. Colombia University Press, New York, 1262 pp.

Doyle, J.J. and Doyle, J.L. 1987. A rapid DNA isolation procedure for small quantities of fresh leaf tissue. Phytochem. Bull. 19: 11-15.

Ghani, A. 2003. Medicinal Plants of Bangladesh with Chemical Constituents and Uses (Second Edition). Asiatic Society of Bangladesh, Dhaka, Bangladesh, 603 pp.

Heywood, V.H. 1993. Flowering Plants of the World. Oxford University Press, New York, pp. 296-299.

Hossain, M.B., Haque, S. and Khan, H. 2002. DNA fingerprinting of jute germplasm by RAPD. J. Biochem. \& Mol. Biol. 35(4): 414-419.

Islam, M., Habib, A., Khan, S, Akter, S., Goswami, B., Khan, B. and Banu, T.A. 2020. Molecular characterization of oil seed Brassica using RAPD markers. Bangladesh J. Sci. Ind. Res. 55(1): 1-8. 
Karande, P.T., Nandeshwar, B.C., Kokane, A.D., Chavhan, R.L. and Dethe, A.M. 2017. Assessment of genetic diversity using RAPD marker among different varieties of rice (Oryza sativa). International $\mathrm{J}$. Trop. Agr. 35(3): 509-516.

Nei, M. 1972. Genetic distance between populations. Am. Natur. 106: 283-292.

Ong, H.C. and Siemonsma, J.S. 1996. Canna indica L. In: Flach, M. and Rumawas, F. (Eds), Plant Resources of South-East Asia, No. 9. Plants Yielding Non-seed Carbohydrates. Backhuys Publishers, Leiden, the Netherlands, pp. 63-66.

Patra, B., Acharya, L., Mukherjee, A.K., Panda, M.K. and Panda, P.C. 2008. Molecular characterization of ten cultivars of Canna lilies (Canna Linn.) using PCR based molecular markers (RAPDs and ISSRs). Int. J. Integr. Biol. 2(2): 129-137.

Poczail, P., Taller, J. and Szabo, I. 2008. Analysis of phylogenetic relationships in the genus Solanum (Solanaceae) as revealed by RAPD markers. Plant Syst. Evol. 275: 59-67.

Rahman, M.O. 2010. Use of Random PCR (RAPD) technology to analyze systematic relationships in terrestrial bladderworts (Utricularia L.). Bangladesh J. Bot. 39(1): 97-102.

Sales, E., Nebauer, S.G., Mus, M. and Segura, J. 2001. Population genetic study in the Balearic endemic plant species Digitalis minor (Scrophulariaceae) using RAPD markers. Am. J. Bot. 88: 1750-159.

Sultana, N., Akhi, S.S., Hassan, M.A. and Rahman, M.O. 2019. Morphological and anatomical investigation among six variants of Canna indica L. Bangladesh J. Plant Taxon. 26(2): 219-230.

Venkatachalam, L.R., Sreedhar, V. and Bhagyalakshmi, N. 2008. The use of genetic markers for detecting DNA polymorphism, genotype identification and phylogenetic relationships among banana cultivars. Mol. Phylogenet. Evol. 47(3): 974-985.

Vilatersana, R., Garnatje, T., Susanna, A. and Garcia-Jacas, N. 2005. Taxonomic problems in Carthamus (Asteraceae): RAPD markers and sectional classification. Bot. J. Linn. Soc. 147: 375-383.

Williams, J.G.K., Kubelik, A.R., Livak, K.J., Rafalski, J.A. and Tingey S.V. 1990. DNA polymorphisms amplified by arbitrary primers are useful as genetic markers. Nucleic Acids Res. 18: 6531-6535. 